\title{
ResearchOnline@JCU
}

This is the Accepted Version of a paper published in the journal Journal of Science Teacher Education:

Lewthwaite, Brian, and Wiebe, Rick (2014) Responding to students' learning preferences in chemistry. Journal of

Science Teacher Education, 25 (3). pp. 263-287.

http://dx.doi.org/10.1007/s10972-013-9369-5 
Responding to Students' Learning Preferences in Chemistry

"There's real strength in the points they made. I can't ignore that."

Responding to Students' Learning Preferences in Chemistry

Brian Lewthwaite

James Cook University

Rick Wiebe

University of Manitoba

Brian.Lewthwaite@jcu.edu.au

Key words: Chemistry teaching, tetrahedral orientation, transformational learning, pedagogical change 


\section{Responding to Students' Learning Preferences in Chemistry}

\section{Introduction}

Current curriculum reform efforts in education and science education in particular encourage students' increased participation in discursive learning practices; that is, those interactions amongst students and teacher in which students share their thinking orally or in writing. As Rivard asserts an increase in student talk around the learning focus becomes characteristic of discursive classrooms (2000). From a cognitive viewpoint, discursive practices are believed to help students learn by encouraging students to articulate and evaluate other's ideas (Kuhn, 2005). Although this endorsement is commonly evidenced in the science education literature (e.g., Duschl \& Grandy, 2008), it is less common but has been advocated for in the chemistry education literature. As suggested by Hoffman and Laszlo (1991), chemistry needs to be framed as a collective and collaborative activity which focuses students on the communication of the chemistry experience both in the written and spoken form. Although recent developments have brought attention to the need for an alternative pedagogy in promoting student understanding of chemistry phenomena through more discursive classroom practices, less attention has been given to how these changes are received by students, especially for those whose first language is not the language of instruction. It is within this context that the research presented here is located.

Reform efforts in chemistry education have more recently and quite singularly focused on assisting students learning by encouraging teachers to adopt a 'triangular planar modes of representation model' (Johnstone, 1991) as a pedagogical framework to assist students in the learning of chemistry (Gilbert, 2005; Gilbert \& Treagust, 2008, Taber, 2013). Johnstone (1991) purports that chemistry learning is made difficult because a deep conceptual understanding of chemistry requires exposure to the three modes of chemistry representation: the molecular (submicroscopic), the symbolic (calculations, chemical symbols and equations) and the macroscopic (tangible, visual, experiential, and most often in chemistry teaching practically-based). In other words, students need to be experiencing, thinking and communicating in these three levels to develop a deep understanding of chemistry phenomena (Laslo, 2001). Judging by the focus of more recent research in chemistry education (for example, Gilbert, 2005; Gilbert \& Treagust, 2008, Taber, 2013), one could argue that Johnstone's exhortation is one of the most influential suppositions for influencing reform-based developments in chemistry teaching today.

More recently Mahaffy (2006) has challenged this model referring to its omission of an essential dimension, the human element. In response to this omission, he encourages chemistry educators to move beyond the triangular planar (which he asserts focus chemistry education on content acquisition) to incorporate a further dimension of experience and communication, thus changing the model to a tetrahedron as illustrated in Figure 1 below. As Mahaffy (2006) states “...this 


\section{Responding to Students' Learning Preferences in Chemistry}

rehybridization emphasizes [the] need to situate chemical concepts, symbolic representations, and chemical substances and processes in the authentic contexts of the human beings who create substances, the cultures that use them, and the students who try to understand them". Mahaffy goes on to elaborate on what this 'human element' might include within chemistry education. He describes the need to develop public understanding and trust through the exploration of contemporary applications of chemistry and the social and environmental issues associated with chemical production and use. Further, he emphasizes the need for students to study the people and stories behind the history and origination of chemistry ideas across the breadth of the world's cultures.
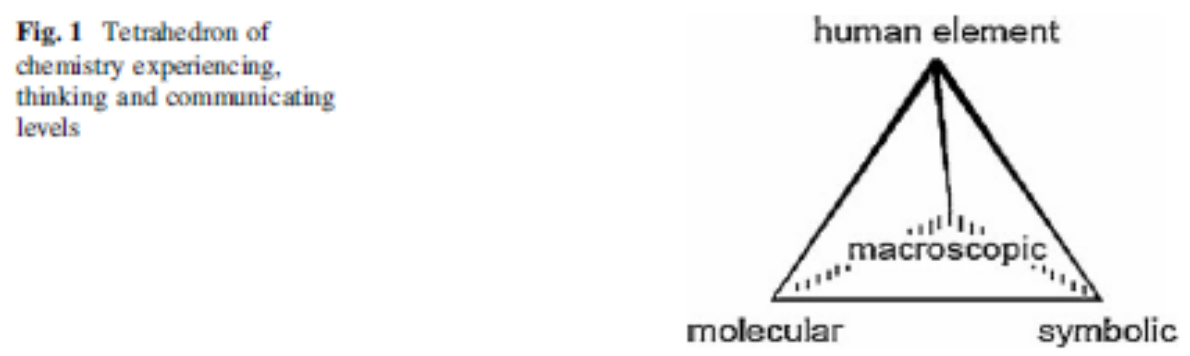

Overall, his advocacy for the inclusion of the human element rests in a supposition that engagement with, learning and communication in and appreciation of chemistry may be hampered by an insufficient integration of the human element into the content of chemistry and a three mode pedagogical framework. This 'tetrahedral' approach not only includes the explicit learning of chemistry, but also includes the learning about chemistry as it is dealt with in society (Burmeister, Rauch \& Eilks, 2012). With this addition, education becomes the most prominent field for learning about how chemistry is embedded in our life and society, including its ecologic, economical and societal impacts (Hofstein, Eiks \& Bybee, 2011). As mentioned by Hoffman and Laszlo (1991) and Laszlo (2001), each of these four dimensions is a 'personalisation' of the nature of chemistry. Each, in itself, is a means by which chemists, and, central to this study, chemistry teachers and their students attempt to live out and articulate in written, oral and visual form the chemistry phenomenon under consideration. As Breiting et al (2005) and De Haan (2006) assert, such chemistry education experiences demand the opening of classrooms and an altered teaching culture, and, accordingly, an altered student experience especially in terms of the discourse of classrooms.

Despite the tenuous status this multi-modal teaching approach may have in fostering student learning and engagement in chemistry, little attention is paid in the chemistry education literature to how students themselves respond to a more discursive classroom environment. How do students respond to the multi-dimensional learning experiences that emanate from teachers teaching towards this tetrahedral orientation, especially with its focus on increased attention to the 


\section{Responding to Students' Learning Preferences in Chemistry}

spoken form? What changes in their 'studenting' (Mason \& McFeetors, 2006) are required as a result of their teacher's changed practice? How do teachers deal with any tension which results from a teaching orientation that is inconsistent with their students' preferred pedagogy? Do tensions that arise lead to changes in a teacher's teaching in a manner consistent with their students' preferred pedagogy? These questions become the focus of the research inquiry presented here.

\section{Context of the Study}

Mahaffy's supposition and advocacy for a tetrahedral orientation currently resonates with reform-based chemistry curriculum development in the province of Manitoba, Canada. The new Grade 11 and 12 chemistry curricula (Manitoba Education, Citizenship and Youth (MECY), 2006 and 2007 respectively) explicitly emphasize a tetrahedral orientation as a pedagogical framework for the teaching of chemistry. It is believed by the Manitoba curriculum development team (of which the authors are members) that this tetrahedral orientation is not, as yet, explicitly underpinning any other chemistry curriculum internationally. For this reason, this research project reported here, under the umbrella of a much larger chemistry education professional development project (Lewthwaite \& Wiebe, 2011), was seen to be an important contribution to the chemistry education community.

Although the theoretical underpinnings of the curriculum are espoused elsewhere (MECY, 2006, 2007), of central importance to the writing team was the need to have students experiencing, thinking and communicating on these four levels (MECY, 2006). For this reason, we believed teachers needed to be representing chemistry so students were experiencing and communicating chemistry in multiple forms. As asserted by Wu (2003) we were committed to encouraging the discursive practices students might conceptually require to move back and forth among these modalities and cognitively interact with various types of representations in a meaningful way. This tetrahedral orientation is evidenced consistently throughout the Grade 11 and 12 chemistry curriculum. As an example, in the teaching of a conceptually difficult concept to understand such as acid strength, students would observe and describe the differences between strong and weak acids at the experimental level (macroscopic); seek to explain their understanding of these differences in properties through their molecular dissociation differences (microscopic) and how this difference is represented through written chemical equations (symbolically) and oral and written descriptions of biochemical processes such as blood $\mathrm{pH}$ equilibrium and stomach digestion in the human body (human element) (MECY, 2007).

As might be expected, the new Manitoba chemistry curricula with its advocacy for a tetrahedral orientation, especially at the Grade 11 level, brings with it an orientation to chemistry teaching and learning that is unlikely to be consistent with current chemistry teaching practice among chemistry teachers. As suggested by Johnstone (1991) and Gabel 


\section{Responding to Students' Learning Preferences in Chemistry}

(1999), most chemistry teachers and, consequently their students, focus primarily on the abstract teaching, thinking and communicating level in the written symbolic form, and, thereby, any effort to bring about reform-based changes to chemistry teaching and learning practice must be accompanied by significant support. As Hoffman and Laszlo (2001) assert, this shift requires teachers and students to engage in a 'language' or communication of chemistry beyond the written symbolic level. As research asserts, a new curriculum is rarely accompanied by teacher change unless accompanied by significant and strategic support (Fullan, 1992). In response to this challenge, the University of Manitoba's Centre for Research, Youth, Science Teaching and Learning (CRYSTAL) embarked on a five-year research and development project to support the improvement of teaching and learning of chemistry in accordance with the intent of the new curriculum and its tetrahedral orientation. Although the teacher development focus of this project is described in another study (Authors), in this study we focus upon students' response to a teacher's teaching and the new curriculum with its tetrahedral orientation. The research questions that are underpinning this reported portion of the study are:

1. How do students, especially students for whom English is not their first language, respond to a change in a teaching orientation, especially one that encourages more discursive classroom practices, that is in accordance with the tetrahedral orientation of the new curriculum?

2. How does a teacher attempt to address the tension that emanates from reconciling their pedagogical aspirations as a teacher and a progressive curriculum's intent for more discursive practices with the learning preferences of his students?

\section{Theoretical Framework of the Study}

This study is informed by two interconnected bodies of literature. These include teacher professional identify and adult learning theory.

\section{Teacher Identity}

The study is located theoretically in the teacher education literature on professional identity, the perception that teachers as adults have of themselves (Cattley, 2007). Similar to the constructivist tenets often touted in the science education and adult education literature, we believe the views of science, in particular, chemistry and self that teachers typically possess are durable, often miss-conceived, and actively developed as a result of an adaptive activity (von Glaserfield, 1995) through their own school experiences. Lamote and Engels' writing on teacher identity suggest, similar to other teacher education researchers (Rots, 2007), that there are various teacher 'sub-identities', one of which is teacher task orientation and central to this study. Denessen (1999) specifies that task orientation focuses on aspects such as the (1) pedagogical relation between teacher and students; (2) the educational goals motivating the teaching; and (3) the instructional emphasis. Of importance to 


\section{Responding to Students' Learning Preferences in Chemistry}

this inquiry is the suggestion by Denessen (1999) that the task orientations are primarily associated with two major ideologies - a less frequently identified but commonly advocated reform-based, student-centered approach in contrast to a more commonly identified content-centered approach. A pupil-oriented ideology will focus on a pedagogical relation that responds to students' learning styles, fosters involvement, educational goals that are social and personal and an instructional emphasis that is more process-oriented. In contrast, a content-oriented ideology will largely disregard students' learning preference, focus on a pedagogical relation focused on discipline, educational goals that are geared towards career development and an instructional emphasis that focuses on product. Building upon Dennison's claims, a content-oriented classroom is likely to be characterized by a univocal discourse dominated by a lecture format where classroom conversation is limited to students sharing their solutions, usually in written form, often with little or no deep thinking (Kitchen, 2004). Any shift in teacher task orientation, as Denessen (1999) suggests, requires a restructuring in one's sub-identity.

\section{Adults Learning Theory: Mezirow's Transformational Learning Model}

We do not see this restructuring as an easy task. Drawing upon the adult education literature (Mezirow, 1981, 2000), we believe that for the teachers involved in this project this redefining of chemistry and their identity as chemistry teachers must be transformative in nature. No simple cursory process in professional development can be utilized to bring about this change. We believe, as suggested by Magolda (2001), that a teacher's identity is dynamic and continually being 'made' as a result of their experiences both passively and, in this study, proactively. We see our roles, through the experiences we provide as teacher educators engaged in promoting the professional learning of our chemistry teachers, as critical in bringing about this change. We believe (and as supported by the chemistry education literature previously cited) that our teachers' view chemistry as a curriculum area premised, primarily, as a body of knowledge grounded mainly in the acquisition of content at the symbolic level through didactic teaching, not through a process of inquiry emphasizing a multi-modal approach

to the teaching and communicating of chemistry and certainly not one responsive to the individual learning preferences of their students. In their case, a new consensus of chemistry and self is required. This new epistemological system (Kegan, 1994) is dependent on the construction of a new or revised interpretation of the meaning of one's experience in order to give new meaning and perspective to an old experience (Mezirow, 1981).

As Mezirow asserts, adult learning often involves a cognitive restructuring involving change in habits of mind, points of view (1981) and, ultimately, behavior. Learning is initiated through triggered or 'disorienting dilemmas' that set the learning process in motion. Mezirow suggests that for the adult learner, the disorienting 'unfreezing' experiences prompt reflection; that is, the examining of long-held, socially constructed assumptions, beliefs and values. This critical assessment 


\section{Responding to Students' Learning Preferences in Chemistry}

of assumptions is central to transformative learning. The disorientation, although a trigger for prompting change, in itself, does not bring about change. Mezirow (2000) asserts that a critical assessment of assumptions then needs to become the forum for discussion. Discussion, especially with colleagues, subsequently, provides the setting for pre-existing and new meanings to be discussed and evaluated. In rational discourse, bias [may be] set aside in order to arrive at a new consensus. Mezirow (2000) suggests that this critical discourse allows opportunity for 'resolutions' that in turn need to be, provisionally, acted upon and, in turn, evaluated. It is through this trial, evaluation and reflective discourse cycle, that new perspectives have the opportunity to be reintegrated into one's life. We believe Mezirow's transformational learning model underpins the learning required to be central and of first-order to science teacher education, and, in the case of this study, our professional development efforts. If teachers of chemistry experience transformation in their views of chemistry and self, we have teachers in their most significant learning. This revising of views of science and self is the heart of in-service science teacher education and the professional development activity to be described.

\section{Methodology}

\section{The Professional Development Project}

In this paper we present the accounts of one teacher who has been a part of the much larger and extended professional development project. Because this project provides the context for this study, we begin by briefly describing the nature of the professional development. The theoretical underpinnings and outcomes of this larger project are described in full elsewhere (Authors). The extended project involved over five years three groups of chemistry teachers from different geographical regions of Manitoba, Canada for a total of 74 chemistry teachers. During the course of a year, teachers from each cohort attend four professional development days focusing on the topics of either the Grade 11 or Grade 12 curriculum. Thus, most teachers, including our case study teacher, had participated in approximately 120 hours of face-to-face professional development.

The sessions typically involve the identification in advance of specific learning outcomes that require a teaching orientation unlikely to be consistent with current teaching practice. Teachers in attendance and facilitators participate in tangible teaching examples (for example, demonstrations, laboratory experiments and investigations, practical applications, computer simulations) that address these outcomes in a manner consistent with the curriculum's tetrahedral orientation. As an example, in the example of strong and weak acids cited earlier, four hours in one session were placed on how teachers could use computer-based simulations to illustrate visually how strong acids in contrast to weak acids dissociate to produce a higher concentration of hydronium ions and, consequently, influence the macroscopic properties associated with a higher 


\section{Responding to Students' Learning Preferences in Chemistry}

conductivity and lower $\mathrm{pH}$ of the resulting solution. Accordingly, various kinesthetic models, manipulative software and web-based simulations were critiqued in terms of their clarity in making the connections between the macroscopic, molecular and symbolic levels. Further, practical examples of the reason behind the role and importance of strong and weak acids were considered in the context of the human body, including the role of hydrochloric acid, a strong acid, in stomach digestion and the homeostatic role of weak acids in the maintenance of blood $\mathrm{pH}$. Sessions were seen as an opportunity to collaboratively assist teachers and facilitators in becoming more familiar and comfortable with the pedagogy associated with the three vertices of the tetrahedron that they are least accustomed to, in particular the human element, molecular and macroscopic. It is estimated that these three dimensions combined for the majority of the focus of the sessions and, correspondingly, the more than 200 resources developed by the project leader and teachers. Because they are regarded as less orthodox teaching strategies, special emphasis was placed on effective pedagogy associated with the use of computer-based visualizations, historical accounts of chemistry ideas, practical applications of chemistry, and engaging macroscopic experiences such as experiments, demonstrations and investigations. Although emphasis was placed on encouraging student and teacher conversation around these modalities, no attention was explicitly given in the professional development to how students might respond to this adjustment.

Finally, at each session consideration was given to how teachers could modify their assessment practices to assess student learning, as an example, of strong and weak acids. In particular, what strategies might teachers use to allow students to communicate their understanding of acid strength in each of these four modalities? In developing an improvement in assessment practices consistent with the tetrahedral orientation of the curriculum, we encouraged teachers to consider the intentions of the new curriculum and how these dimensions might be addressed through assessment. In Table 1, we provide the assessment framework we have used with teachers. It is noteworthy that our school system in Manitoba advocates

standards-based assessment as evidenced in students' competence on each of these four levels. As an example, in the study of strong and weak acids, in more orthodox curricula assessment might focus on the macroscopic and especially the writing of equations at the symbolic level. In contrast, teachers in Manitoba would be encouraged to assess student understanding of the behavior of strong and weak acids at the molecular level through communicating understanding through visual representations and explaining in words how this behavior has implications for the use of strong and weak acids in particular contexts.

Capturing Teacher Practices \& Aspirations 


\section{Responding to Students' Learning Preferences in Chemistry}

The instrument used to gauge teacher development in this project was the Chemistry Teacher Inventory (CTI) (Appendix One). The development process of the CTI is detailed elsewhere (Authors), but it is important to recognize here that it has been developed specifically for this project within the context of the Manitoba curriculum and its' tetrahedral orientation and is based upon what students primarily, and the literature and teachers involved in this project suggest influence student learning in chemistry. Its development primarily involved 428 students in the participating teachers' classrooms who described the teacher actions that enabled and constrained their learning of chemistry.

Integral to this paper's focus was frequent evidence in the responses gathered of student dissatisfaction with the curriculum's orientation. As an example, some student identified "discussing results with classmates" as a teacher behavior that least assisted in their learning whereas most students identified "I learn best when we are expected to discuss things in groups". As the professional development facilitators processed the student responses, we could see that many behaviors viewed as progressive by the focus group which encouraged multi-dimensional exposure to and communication in chemistry were not being acknowledged by some students as contributors to their learning. In fact, these progressive behaviors were often seen as impediments to their learning suggesting that this, in theory, progressive learner-centered curriculum was not connecting to the individual learning preferences of several students. This outcome became the focus of the study presented in this paper. It, in itself, became the source of puzzlement for exploration for both the authors and teacher involved in the study.

\section{Substantiating Teacher Practices \& Indicating Student Aspirations for Their Teacher's Teaching}

In order to 'trigger' teacher reflection-on-action (Mezirow, 2000) and destabilize teachers' practices as a means of motivating teachers to improve their pedagogy and become responsive in accordance with their students' preferences for their learning, a modification of the CTI was developed for students. The Chemistry Classroom Inventory (CCI) presented in Appendix Two is a student version of the CTI and asks students to consider their current chemistry classroom and the frequency of teacher behaviors and classroom characteristics they experience. Student forms of instruments adapted from the teacher response instrument are commonly used in Learning Environment Research for a variety of purposes (Fraser, 1998a, 1998b). First, it corroborates teacher perceptions of their own teaching. That is, do students' responses correspond with a teacher's perceptions of their teaching behaviors? Second, in order to foster teachers' self-study of their teaching practices (Berry, 2007), students are asked to indicate whether they would like to see these displayed more frequently in order to foster their learning (+), less frequently (-) or remain the same (0). 


\section{Responding to Students' Learning Preferences in Chemistry}

During the fifth and final year of this larger professional development project, we sought to include teachers in a self-study initiative in which they, individually, would complete the CTI, and their students, as well, would complete the CCI. Eight of the teachers were responsive to this line of inquiry. A variety of external factors such as travelling distances and extracurricular responsibilities prevented a larger number of teachers from participating in this phase of the project. One 'professional development' session during the fifth and final year (in addition to the four sessions these teachers were already attending) provided opportunity for these eight teachers to individually collate these data and identify patterns in the data to prompt their thinking about their teaching in response to their students' learning. As suggested by Mezirow (1981), we believed these data would be triggering experiences, especially if students' perceptions were different from that of their teachers. It was anticipated that in fostering self-study these considerations and ensuing critical discourse with cohort colleagues, the authors as professional development providers and students would foster teacher development towards teaching that supports their students' learning. It was also evident from the initial collected data, that that there was likely to be considerable variability among student responses indicating that a tetrahedral orientation to the experiencing, thinking and especially communicating levels of chemistry may, in itself, not be responsive to all students' learning styles or at least, means by which they prefer to communicate their chemistry understanding.

\section{The Research Participant \& Instrumental Case Study}

Although eight teachers participated in this part of the study, we present the data from one teacher only, Tyler. Although the context of this intervention is eight teachers drawn by their self-selection from a much larger number of teachers involved in a five-year professional development program, the study presented here focuses on one case. As described by Stake (1995), this qualitative study is categorized as an instrumental case study where a particular case involving a teacher, his students and a new chemistry curriculum is of interest in all its particularity and ordinariness. It, in itself, reveals a story. The instrumental case study is best utilized in a situation where there is a research question similar to ours that seeks answer to puzzlement and a need for general understanding and feeling that we may get insight into the question by studying a particular case (Stake, 1995). In instrumental case study what is most important is the identification of the revealing case rather than the typical case. Although any of the eight teachers might provide insight into how (1) students respond to a change in a teaching orientation that is in accordance with the new curriculum and (2) teachers address the tension that emanates from reconciling their pedagogical aspirations as teachers and a progressive curriculum's intent with the requests of their students, we choose but one. Rather than examining trends in qualitative and quantitative data from the eight teachers, we choose but one 'rich' case. Inherent within Tyler's account over the duration of the five-year project was 


\section{Responding to Students' Learning Preferences in Chemistry}

evidence of tensions between his aspirations for teaching and his students' preference for his teaching elicited through questionnaire completion; group discussions with his colleagues; face-to-face, by email and telephone conversation with the authors; and follow-up discussion after his dialogue with students about his teaching.

Instrumental case study encourages a narrative inquiry approach (Clandinin \& Connelly, 2000) where the focus is on understanding Tyler's learning as a response to listening to his students. Overall, we sought to make sense of the respondent's personal story about classroom learning and how these stories intersected (Glesne \& Peshkin, 1992). We sought to understand students' and teacher's behaviour from their own frames of reference. We then ensured that these interpretations were verified by Tyler and altered to be consistent with his perspective through his reading of this manuscript. Because this instrumental case focuses upon one candidate's account, the study presented here lacks generality, notwithstanding that it does provide teacher educators with considerable insight into a program intervention and the outcome of this intervention in the response of a single participant and his students.

Tyler is a senior chemistry teacher at a large urban school near a provincial university in a large Canadian city. He has taught at this school for nineteen years and, because of the nature of the school and those who select to study Chemistry teaches high matriculation students. His students, most of whom are English as Additional Language (EAL) learners, are strongly motivated, high achieving students. It is an implied expectation of the school and its' families that students upon graduation will attend university (likely to be the one in the school's vicinity) and most students will seek entry into professional science-related careers. The school prospectus asserts, "Graduates of City School (pseudonym) are prepared to excel in their post-secondary scholastic studies. Our history shows we have a legacy to be proud of and this is well-secured by the practices of our classrooms today." Tyler estimated that the majority of students in his chemistry class in any given year will, indeed, gain entry to professional colleges such as engineering, pharmacy and dentistry. What drew us to Tyler's case was the tension between his aspirations for teaching, especially in promoting more discursive practices, and students' preference for his teaching to foster their learning. As the professional development program progressed, we could sense through Tyler's comments at the cohort professional development meetings that his advocacy for the tetrahedral orientation

of the curriculum and subsequent teaching practices, including assessment, were the source of considerable tension among his students.

\section{Results}

Tyler, like the other professional development participants, had self-selected to participate in the five-year program and remained a part of it for its duration. As Kane and Maw (2005) jest, he was 'one of the willing' and as Fullan (1992) 


\section{Responding to Students' Learning Preferences in Chemistry}

suggest, we believe he showed 'readiness' for change. In this section we provide detail about Tyler's development primarily as a chronological narrative over five years through the professional development program describing his development and the influences on his development, especially with emphasis on the influence of student voice on his practice.

\section{Tyler in the First Year of the Project}

Under the authors' request, he, along with all the cohort participants, completed the CTI in the first year of the project. As well, in the first year of the professional development he was asked in an interview, as were all participants, about his teaching orientation and how he thought it corresponded to the tetrahedral orientation of the new curriculum. He responded:

I have always wanted my students to do well academically and I think over the years I have become too focused on covering the material and just getting them through the course and ready for university. There are a lot of new ways to get the content across and I want to focus on that. This professional development opportunity came up just at the right time. I hadn't looked at the [new] curriculum yet, but I knew I wasn't that happy with how I was becoming more focused on content and the same old strategies. I think the curriculum is at where I am. I can see it will bring me back to focus on students and their learning. I look forward to it. I am not too sure though about my students. They like things to be pretty straight forward.

Further, he, like all the other teachers in the professional development program, was asked in this preliminary interview how he taught selected topics in Grade 11 or 12 Chemistry. He was asked to describe a chemistry lesson that a research assistant would observe, for primarily verification purposes, in the near future. He focused in the discussion on how he assisted students in understanding the difference between weak and strong acids, the example cited earlier in this paper. Tyler gave the following description of how he assisted students in differentiating between strong and weak acids.

Well, I use the [numerical] Ka values. The numbers tell them how much the acids dissociate. Large Ka [values] indicate strong acids; small [Ka values] indicate weak acids. It's pretty straight forward.

When asked what the focus of his explanations was in teaching for learning, Tyler stated:

We do a lot of experimental work - labs and the sort. There are notes to support what we see. But the focus is on them making connections between the experimental work and the theory.

When asked if he did experimental work to illustrate differences between strong and weak acids, he said"

No. It's pretty straight forward. The experimental work is primarily in the titration-stoichiometric work we do and that takes several classes. 


\section{Responding to Students’' Learning Preferences in Chemistry}

Similar to most participants in the program (Authors), Tyler's response indicated a reliance on a symbolic explanation of acid strength of Ka values (which are numerical representations of degree of acid dissociation) void of any reference to macroscopic or molecular experiences that might assist students to understand the significance of Ka values.

As mentioned, Tyler was one of the sixteen teachers observed for a one hour chemistry lesson in the first year of the study. Using a Chemistry Teaching Observation (CTO) protocol (not included), the frequency of the 33 chemistry teaching behaviors identified as contributors and inhibitors to learning were observed. Although some variation among the research assistant's observed teaching (as evidenced in the CTO results) and Tyler's description of his teaching both on the CTI and in the interview, we concurred that these data corroborated his view. In the observation of Tyler's lesson on acid strength, the explanation took four minutes. The focus was solely on Ka values. There was no reference to any macroscopic, molecular or human element applications. In the teaching sequence, the explanation was given orally. In the next few minutes of the class, notes were written on the board which simply represented, through equation, dissociation and the formulaic relationship between dissociation and acid strength. These included:

$\mathrm{K}_{\mathrm{a}}$ is the mathematical representation of acid strength as a result of its dissociation in water.

For the acid HA: $\mathrm{HA}(a q)+\mathrm{H}_{2} \mathrm{O}(l) \rightleftharpoons \mathrm{H}_{3} \mathrm{O}^{+}(a q)+\mathrm{A}^{-}(a q)$

$$
\mathrm{K}_{\mathrm{a}}=\frac{\left[\mathrm{H}_{3} \mathrm{O}^{+}\right]_{\mathrm{e}}\left[\mathrm{A}^{-}\right]_{\mathrm{e}}}{[\mathrm{HA}]_{\mathrm{e}}}
$$

Although he then asked students, "Is this ok? Any questions?", there were no responses from students. Our observations corroborated Tyler's account of his teaching. There was a reliance on a symbolic explanation of acid strength

with reference to Ka values void of any reference to macroscopic or molecular experiences that might assist students to understand the significance of Ka values.

\section{Tyler in the Third Year of the Project}

In year three, after seven professional development days, teachers again completed the CTI. No observations of classroom practice were made although Tyler was interviewed about his practice. His comments included:

Working with a group of colleagues focusing on improving teaching and learning makes its way into my classroom daily. I just give more thought and consideration to what we do and I have the background to do that. I am taking more time to teach and ensure my focus is on teaching for learning. 


\section{Responding to Students' Learning Preferences in Chemistry}

As an example, we asked about a topic he has recently taught. In reference to the Gas Laws topic described earlier in the article he stated:

The curriculum makes it clear you need to spend time making sure students understand the relationships among volume, pressure and temperature. The experimental work, I realize now, is essential to them coming to understanding of why the graphical representation is not linear and there is not only a direct or indirect relationship between things like volume and temperature, but that the relationship is a constant. If you don't include that, they really don't understand.

Similar to most program participants, Tyler's CTI results had moved over the three years to show he, along with his colleagues, was using a much broader range of strategies addressing all four modalities of chemistry representation in his teaching (Authors). Since the 64 hours of professional development over the first three years encouraged teachers to share of their own pedagogy and utilized resources, we were commonly introduced to the accounts of the experiences Tyler was providing for his students. These were always consistent with the tetrahedral intent of the curriculum. In fact, on several occasions Tyler introduced us to experiences he was providing for his students. As an example, he demonstrated to his cohort how he used computer-based visual simulations to show electronic, molecular and ionic activity in complex chemical processes in galvanic cells. He then used these images to prompt student discussion of the changes occurring among atoms, electrons, ions and molecules before students wrote chemical equations to represent these processes. This gave us evidence that he was attempting to foster a multi-modal pupil-oriented discursive classroom devoted to considering students' solutions and taking these responses seriously in an effort to encourage additional student talk and deeper student thinking (Kitchen, 2004).

\section{Tyler in the Fifth Year of the Project}

Despite this progress in Tyler's teaching over the five years, we wanted Tyler to ensure that his teaching was responsive to the learning preferences of his students. In the section that follows we describe the methods and outcomes of the methods used to prompt Tyler's deeper thinking of and change in his practice through the collection of data and associated critical discourse in response to these data. At the start of the fifth year of the program in the first month of the teaching year, teachers were again asked during an interview to reconsider their initial teaching orientations of the topic they had selected at the commencement of the project. Tyler was asked to reconsider how he differentiated between strong and weak acids. He stated: 


\section{Responding to Students' Learning Preferences in Chemistry}

I can't believe that is how I approached it [acid strength]. Last semester I used conductivity apparatus to show how acids behave differently when water is added. I wanted them to see, I mean really see, how the conductivity of acids differ. This conductivity difference gives evidence that there is a difference in dissociation. I then showed them a [web-based] illustration that shows how the acids behave differently. Ultimately, I get to the Ka values. I can't believe I just used to jump to this [symbolic form]. Now, the Ka values are only a final component of the teaching sequence. The values make sense to them. At least, I require them to show me that they make sense of the values. I think before they were just numbers I used to identify strong and weak acids, but I doubt if they really understood what the values represented.

He was asked to identify what had contributed to his change in pedagogy. He stated:

[Echoing his initial interview] This professional development focus and the new curriculum came along at the right time. I was wanting to move ahead and focus more on developing their understanding [of chemistry ideas] and that is what I saw in the PD and the new curriculum. [Students] can manipulate formulas and do any sort of calculation, but they don't really understand the chemistry behind the numbers and symbols. I wanted to be challenging them to think. I was committed to working towards a change in my teaching over the five years and the [school and divisional administration] were supportive of this.

Further, we asked Tyler about his students and their response to his efforts. He commented:

This is where it becomes an issue. Here I am making this progress and know my teaching has changed dramatically, but I don't know if my students are progressing. [It's only a month into the new school year and] I am concerned about how they are responding. I find the students really cautious about my teaching. I am not sure if that's caution about me or the chemistry or maybe it's both. We'll get there."

Under the authors' request, he, along with all the cohort participants, completed the CTI at the start of the fifth year of the project which was two months into the teaching year. Although the participants' development over the five years was monitored statistically through the CTI (Authors), for this paper's purpose what was most evident from his inventory at this stage (Appendix One) was the breadth of teaching behaviors representative of the four dimensions manifest in his teaching of chemistry. Noteworthy in his instrument response was the perceived frequent use of behaviors consistent with a tetrahedral orientation to the teaching of chemistry that required students to experience, think and communicate on these dimensions. As examples, he perceived that he often used visual images to clarify Chemistry ideas (Item 3), explained how chemistry ideas relate to students' lives (6), talked about this historical development of chemistry ideas (7), required students to carry our set 


\section{Responding to Students' Learning Preferences in Chemistry}

labs (8), asked students to explain what is demonstrated (11), used computer-based simulations to clarify Chemistry ideas (5), sought to ensure students understand what a formula means before calculating (14), had students explain chemistry ideas at the molecular level (15), referred to history of chemical applications (24), explained ideas as students copy notes (32), and assessed student learning by tests and experimental activities ( $27 \& 33)$. He also perceived he always ensured students grasped ideas before moving on in instruction (23), had students to carry our mini labs and experiments (26), provided students with lots of examples to help assist students in their learning (28), assisted students with their work as necessary (28), and used everyday examples to communicate Chemistry ideas (31). In all, his comments provided significant support for his perception that he uses a variety of strategies to get across Chemistry ideas (16).

Noteworthy in his CTI comments are his preferences for changed practice using the + (I would prefer to do this more), 0 (I would prefer for this practice to remain the same) and - (I would prefer to do this less). Of importance to this study is that Tyler, at this stage of the professional development program, saw little requirement to decrease certain practices. In fact, the only practice he wanted to decrease in use was assessing student learning by tests. In contrast, there were many progressive behaviors that he was frequently, often or always using, and he perceived he did not desire to use these more frequently suggesting he had come to a point of congruence between his aspirations for teaching and perceived teaching performance. As well and despite that he had already make significant progress, there were many behaviors he wanted to use more frequently, even though they were being used frequently. As examples, he sought an increase in students explaining results by discussing with a group, asks students to explain what has been demonstrated, requires students to explain chemistry ideas at the molecular level, uses manipulatives to help students understand what is happening at the molecular level, and the history of chemical applications is talked about in my classroom. Although he perceived he was currently using these frequently, he also suggested that some of these are teaching activities he would prefer to use more often. Emphasis

within these behaviors was a teaching orientation that emphasized the macroscopic, human element, and, especially molecular dimensions within a dialogic environment. The completed inventory also indicated he continued to often use behaviors that focus on the symbolic dimension such as performing calculations in class, performing calculations on tests and assigning problems from texts. He also indicated his preference was to not improve the frequency of these behaviors, in fact, desiring to less frequently spend time assigning problems from texts and assessing student performance through tests.

\section{Examining My Own Practice}

Under the authors' request, two weeks after he had completed the CTI in the fifth year of the project, he had his students complete the CCI. With the collected data, he attended a professional development day with the seven other teachers 


\section{Responding to Students' Learning Preferences in Chemistry}

and first author in which the data were to be processed manually and compared. Tyler's Chemistry Teacher Inventory (Appendix One) results were compared and discussed with his colleagues at a professional development day in which their progress as teachers and future pedagogical aspirations were discussed. At this stage, and quite purposely, teachers had yet to process the Chemistry Classroom Inventory results from their students' responses. Tyler's results pertaining to the perceptions of his own teaching were indicative of a tension existing between his developing actions and his students' receptivity to these changes.

Certainly there is a change in my teaching, but I [continue to] wonder about the [student] response. I focus on wanting them to learn and go beyond just the calculations. I know they find [this tetrahedral emphasis] more challenging. I think it's better for us all, but I don't think anyone [of my students] is convinced.

Evident within Tyler's comments was an indication of what he thought was best for his students and, yet, an uncertainty about how his students were responding to his teaching. Also evident in his comment was how he was focused upon wanting them to learn and, more important to this study, how they should learn, but, as yet, not giving evidence that he was aware of students' preference for what is learned or how things are learned. It was our belief that at this stage of Tyler's professional journey, his lack of awareness of his students' preferences for his teaching and his, assumed to be, current and correct teaching approach was yet to provide the disorienting experience Mezirow (2000) suggests is essential to contribute to transformational adult learning.

\section{Examining My Students' Response to My Teaching}

Following the preliminary discussion about their teaching based upon their completed CTIs, the eight participant teachers were provided an hour to process the results of their students completed CCIs. 24 students in Tyler's Grade 11 completed the CCI. He processed and analyzed the data collected looking for patterns and trends in the students' responses. He did this by looking at the frequency of comments for each item and the suggested increase or decrease requested for each item. Most importantly the participants were asked to identify tensions between their aspirations and their students' learning preferences and among students' preferences. An example of one of Tyler's student's completed CCI is presented in Appendix Two. As well, an abbreviated analysis of the results from Tyler's class completion of the Chemistry Classroom Inventory is presented

in Table 1. The items presented are those that Tyler himself identified as items of tension - items where his perceptions of preferred frequency of use were different than his students. In brief, these items under consideration were those that most students wanted to be used more or less frequently and he, in turn, wished for the same behaviors to be correspondingly used less or more frequently. 
Responding to Students' Learning Preferences in Chemistry

Table 1

Perceived Frequency of Use and Preference for Use of Teacher Behaviors

\begin{tabular}{|c|c|c|c|c|}
\hline $\begin{array}{l}\text { Item } \\
\text { Number }\end{array}$ & $\begin{array}{l}\text { My Perceived } \\
\text { Usage }\end{array}$ & $\begin{array}{l}\text { My Preference for } \\
\text { Increase }(+) \text { or } \\
\text { Decrease }(-)\end{array}$ & $\begin{array}{l}\text { Student } \\
\text { Perceived Use }\end{array}$ & $\begin{array}{l}\text { Student } \\
\text { Preference for } \\
\text { Increase (+) or } \\
\text { Decrease (-) }\end{array}$ \\
\hline $\begin{array}{l}\text { 7. We talk about the } \\
\text { historical } \\
\text { development of } \\
\text { chemical ideas }\end{array}$ & Often & Remain the Same & $\begin{array}{l}\text { Always (3) } \\
\text { Frequently(14) }\end{array}$ & $\begin{array}{l}\text { Decrease (14) } \\
\text { Remain the Same } \\
\text { (3) }\end{array}$ \\
\hline $\begin{array}{l}\text { 10. I am provided } \\
\text { with pre-written } \\
\text { notes that may be } \\
\text { discussed }\end{array}$ & Never & Remain the Same & Never (17) & Increase (17) \\
\hline $\begin{array}{l}\text { 11. I am asked to } \\
\text { explain what has } \\
\text { been demonstrated }\end{array}$ & Often & Increase & $\begin{array}{l}\text { Frequently (12) } \\
\text { Always (5) }\end{array}$ & $\begin{array}{l}\text { Decrease (15) } \\
\text { Remain the Same } \\
\text { (2) }\end{array}$ \\
\hline $\begin{array}{l}\text { 15. I have to explain } \\
\text { chemistry ideas at } \\
\text { the molecular level }\end{array}$ & Often & Increase & $\begin{array}{l}\text { Frequently(11) } \\
\text { Always (6) }\end{array}$ & $\begin{array}{l}\text { Decrease (14) } \\
\text { Remain the Same } \\
\text { (3) }\end{array}$ \\
\hline $\begin{array}{l}21 . \text { I am expected to } \\
\text { explain results by } \\
\text { discussing with my } \\
\text { group }\end{array}$ & Sometimes & Increase & $\begin{array}{l}\text { Frequently (15) } \\
\text { Always (2) }\end{array}$ & $\begin{array}{l}\text { Decrease (8) } \\
\text { Remain the Same } \\
\text { (3) } \\
\text { Increase (6) }\end{array}$ \\
\hline $\begin{array}{l}27 . \mathrm{I} \text { am assessed by } \\
\text { tests }\end{array}$ & Often & Decrease & Frequently (17) & $\begin{array}{l}\text { Remain the Same } \\
\text { (4) } \\
\text { Increase (13) }\end{array}$ \\
\hline $\begin{array}{l}29 . \text { We work } \\
\text { together and help } \\
\text { each other on } \\
\text { activities and } \\
\text { problems }\end{array}$ & Sometimes & Increase & $\begin{array}{l}\text { Seldom (2) } \\
\text { Frequently (15) }\end{array}$ & $\begin{array}{l}\text { Decrease (5) } \\
\text { Remain the Same } \\
\text { (8) } \\
\text { Increase (4) }\end{array}$ \\
\hline
\end{tabular}

In general, the responses from his students validated Tyler's perceptions of use. In Table 1 the behaviors' perceived frequency of use by both Tyler and his students correspond. There were no major differences in perception. In contrast, the preference for the frequency of use of each of these behaviors differed significantly between Tyler and his students. Also, rarely did the preferences for use among students differ within his class. Only in items 21 and 29 which pertained to collaborative communication patterns among students did a few students share Tyler's optimism for an increase in these 


\section{Responding to Students' Learning Preferences in Chemistry}

behaviors. Overall, Tyler inferred from these data that the pattern of student preference was for a non-discursive classroom with emphasis on assessment through summative tests and reduced emphasis on human element application. It was not surprising to the authors that this tension had a pronounced destabilizing influence on Tyler's perception of the progress he had made. He commented within the context of the group's discussion:

I knew there was some dissatisfaction, but I didn’t think it was THIS serious. I really think I am challenging them to a deeper understanding of chemistry, but they fail to realize this.

As a group we discussed the implications of the data for the teachers' teaching and their students' learning. In most teachers' cases, the discrepancy between teachers' aspirations and students' preferences were associated with a shift toward assessment practices that acknowledged chemistry as multi-dimensional in its nature. In Tyler's case, the tension was not only evident in students' preference for traditional assessment practices but also a univocal, less discursive classroom. Some discussion revolved around the perceived source of these tensions. As Tyler suggested:

My students are really motivated and quite competitive. They push each other and aren't into sharing their work. I

know they would prefer to work alone, and I know I challenge them out of their comfort zone. It's good for them in the long run.

It was agreed by the participants of this professional development day that any further inferences from their especially in inferring reasons for student preferences would be purely speculative. In Tyler's case we could see the source of the tensions was in his belief that the source of the problem belonged to his students, not him. All teachers believed that these data would support discussion with their students about how their teaching practices could be modified to suit their students' performance styles.

\section{Using the Data as a Foundation for Critical Conversations with Students}

As a group, we discussed how this consultation could occur. Informing our dialogue were several of the principles exhorted by Kane and Maw (2005) as foundations for an effective consultation process with students. It was important for students to realize that this exercise and its outcomes were of value and relevance for them as learners and, especially their teacher as a learner. They were given agency to help improve his teaching. Second, students needed to be assured that there were no punitive repercussions of their contributing to the dialogue in terms of teacher judgment, especially in assessment procedures. Third, teachers needed to affirm that their role was to provide time for response, listen and, through reflective consideration, respond to what students were saying in terms of their ongoing teaching considerations and actions. We 


\section{Responding to Students' Learning Preferences in Chemistry}

present here Tyler's account (because through university ethics protocols we were unable to collect first-hand data) of the general themes gathered from the responses provided by his critical discourse with his students.

Tyler decided he would take time during an upcoming chemistry lesson in early April and the final semester of the five-year study to present the data from his CTI completion and his students' CCI completion. He told his Grade 11 students in advance of his intentions and the aforementioned principles that would guide the discussion. He first presented to his students the areas where there was congruence among teacher and students and then Table 1 which represented the incongruence between students and teacher and among students. During the 30 minute data presentation and, not surprisingly, brief ensuing discussion, Tyler identified that the dialogue the data prompted solicited responses from only a few students. In response to this outcome, during that class and subsequent classes, Tyler talked with students about the data, informally and usually individually, as opportunity arose such as prior to or after class. The students were satisfied that the data presented were representative of their perceptions. They acknowledged that although he was working very hard to support their success in chemistry, there were some areas where he was placing too much emphasis and this was disconcerting for most students. They acknowledged that his teaching was varied and provided them with a breadth of experiences that gave them exposure to chemistry in a way that they had not experienced before through their introduction to chemistry in Grade 9 and 10 as part of a mandated provincial General Science course. They affirmed that he was prompting them to be more communicative and, in one student's perceptions, Chemistry was "a bit like English" Literature class now where they were supposed to be talking and "explaining things" or "having to talk" as another one said. One student, an English as an Additional Language (EAL) student said students typically "liked" science and mathematics more than other subjects because they weren't "put on the spot" to explain things so much, implying they were being "put on the spot" in Tyler's Chemistry class. He said he sensed students were "not accustomed" to the dialogue he was encouraging in Chemistry. Students' primary focus of concern was on how the assessment practices had changed from Grade 9 and 10. Students agreed that many felt they were getting lower marks because the assessment had become more "wordy" implying that before and in other subjects like mathematics and physics they were just mainly working with calculations and equations at the symbolic level and this had changed in Chemistry. Usually it was just summative determined 'tests' that determined their marks and now, even on tests "we have to explain things all the time now". As one student said, "The rules had changed". They all agreed "being given pre-written notes" (Item 10) would help them to learn, especially if they had to "explain things now". On a final note, he said students gave no conclusive reasoning for the variability in items 21 and 29 associated with their divided 


\section{Responding to Students' Learning Preferences in Chemistry}

response to collaborative communicative activities other than some students "like talking more" and "use that as time to catch up on the gossip".

\section{Post-Consultation Discussion and Final Observation}

Tyler contacted the first author a few days later in mid-April to discuss the outcomes of the consultation with students. Tyler's comments focused on two aspects, both reflecting his ongoing deep consideration of the discussion. First, he commented on the 'strength' of students' comments both in how the responses they provided on the CCI were, overall, consistent with his and how they were so insightful for their reasons for the discrepancies between his aspirations and students' preferences. Tyler commented:

I can't get out of my thinking how accurate their thoughts about my teaching are. I had told them when they completed it [the $\mathrm{CCI}$ ], they needed to think about the questions and take it seriously [like we were encouraged to make clear]. They did. I was really surprised that they [the ones that had responded] had a sense of the real issues. I was amazed they were thinking about how things had changed for them from Grade 10 [last year with other teachers] to Chemistry [with me this year]. Their answers were so to the point. There's real strength in the points they made [even though there were few]. I can't ignore that.

Second, he emphasized his ongoing lack of resolution with their comments, but a personal desire to respond to what they were saying. He stated:

You know, we talked so much [in the professional development program] about teaching for learning. That's what I'm committed to. But, you know, it was what $I$ thought they needed to help them learn. I realize now I need to listen to my students and hear what they're saying to really help them along [in their learning]. It's like there's another level I need to move to and I see it as a challenge. I haven't sorted that one out yet. I think our school has a lot of work to do in this area, especially if [many students] are thinking some students are really being short-changed. I've never thought about how these [changes in my teaching in response to a new curriculum] can favor some [students] over others.

Although the formal professional development project had concluded, eight months after the discussion with his students and into a new school year, Tyler commented in an e-conversation with the first author:

I realize now that before I was making all the calls about what was happening [in my classroom and in teaching] and now I'm just more aware that some of the things I require of them, especially the emphasis we place on verbal communication and those things that are assessed are not to everyone's liking. I've just made it very clear [in 


\section{Responding to Students' Learning Preferences in Chemistry}

requesting more discursive practices] that I'm there to support them and I'm aware that it isn't an easy ask. At the start of the year we spend a class looking at the orientation of the curriculum and what this means in terms of how we will be spending our time in class [on each of these modalities]. We also look at how this [tetrahedral orientation] influences assessment and their need to be proficient on each level [especially in their communication of understanding]. I realize that some students will find some of the [more discursive] modes more difficult to communicate. I provide more time for them to respond and encourage responses from everyone. The pairing of students to discuss things works better too. I make it clear I need their input [in an ongoing manner] though and they respond well to this. I thought they'd see me as a bit crazy if I was asking them for advice about teaching better.

A final observation of Tyler's chemistry class in the topic of acid strength occurred a few days after this dialogue, nine months after the conclusion of the professional development. The observations made and systematic documenting of the 33 teaching behaviors on the Chemistry Classroom Observation Protocol indicated that there was little disagreement between the comments made in the his final interview and the Chemistry Teaching Inventory. Macroscopic experiences and molecular representations using on-line simulations were used to assist students in understanding symbolic representations of acid strength. Students were expected to observe and discuss and record their observations. As well as they observed the simulation they were encouraged to orally communicate their observations of what electrons, ions, atoms and molecules were doing and how this corresponded to a symbolic equation. What was most notable in the 50-minute observation was Tyler's explicit effort in encouraging students to communicate orally in pairs as a result of what they had observed. Within this single class, Tyler provided six opportunities for students to dialogue in pairs around key ideas in the lesson. As examples, he provided opportunity for students to (1) consider what might be observed when equal amounts of acids were added to water and tested for $\mathrm{pH}$ and conductivity and (2) explain what was observed in demonstrating strengths between weak and strong acids. Most evident in his pedagogy was explicit attention to scaffold students in their communication within the modalities of chemistry. Students volunteered responses to the class after peer interchange. His follow-up interview with the author provided insight into this continuing responsiveness to students:

I'm glad how it is going. Today was a good lesson. They have progressed and so have I. I just try to make it fit with them. I need to be patient and allow time for their [oral] response [and discussion with peers]. Before I just moved through it thinking that it all made sense. Now, through what I hear from them, I just have a much better sense of their learning. 


\section{Responding to Students' Learning Preferences in Chemistry}

\section{Discussion}

The Manitoba chemistry curriculum with its explicit advocacy for a tetrahedral pedagogical orientation requires a considerable adjustment in chemistry teaching practice (Johnstone (1991, Gabel 1999). Despite this challenge, the adjustment we see evidenced in Tyler's thinking and action gives indication of a significant process of change likely as a result of both the professional development and his students' assertions. Using Dennesen's typology on teacher identity and, specifically, the sub-identity of task orientation, Tyler's initial teaching was characteristic of a content-oriented classroom characterized by a univocal discourse dominated by a lecture format where classroom conversation was limited to students sharing their solutions, usually in written form, often with little or no deep thinking (Kitchen, 2004). Tyler gives clear evidence of a shift in teaching over the five years towards a pupil-oriented discursive classroom devoted to considering students' solutions and taking these responses seriously in an effort to encourage deeper student thinking through additional student talk and expression of understanding, especially in assisting students in making connections among the multiple modes of chemistry representation. As Dennesen asserts, any shift in teacher task orientation, a sub-component of teacher identity, requires restructuring assumptions, beliefs and, ultimately, practices. As Mezirow asserts the disorienting 'unfreezing' experiences provided by the CCI data prompted reflection; that is, the examining of long-held, socially constructed assumptions about teaching practice, especially in regards to the assumption that a tetrahedral orientation would automatically be welcomed by students. This critical assessment of assumptions was central to his learning. The disorientation, although a trigger for prompting change, in itself, did not bring about change. The critical assessment of assumptions (Mezirow, 2000) then needed to become the forum for discussion. Discussion, especially with students, colleagues and the authors, subsequently, provided the setting for pre-existing and new meanings to be discussed and evaluated. This critical discourse allowed opportunity for 'resolutions' that in turn needed to be, provisionally, acted upon in Tyler's teaching and, in turn, evaluated. It was in this

phase that Tyler committed to scaffolding students in engaging in more discursive practices. It was through this trial, evaluation and reflective discourse cycle, that Tyler's perspectives had the opportunity to be reintegrated into his teaching practices in a manner that supported students' talk and writing around the learning focus.

It is evident from Tyler's narrative that his students had the capacity to provide accurate and well-articulated views on learning and the practices that support their preferences for learning (Kane \& Maw, 2005). As well, as Cook-Sather (2002) identified, they were able to assume the position of authorities on learning and teaching as afforded the opportunity. As Tyler asserts, "There's real strength in the points they made. I can’t ignore that". Despite this awareness, Tyler's final comment referring to "they'd see me as crazy if I was asking about teaching better" indicates his ongoing hesitation in drawing 


\section{Responding to Students' Learning Preferences in Chemistry}

students into providing consideration of how he can improve his teaching to suit their needs. As identified by Wu (2003), Tyler's explicit scaffolds were crucial to support students in the development of the discourse necessary to meaningfully navigate among chemistry's modalities, especially outside the symbolic.

Further, Tyler's account makes clear that as much as a change in curriculum usually requires a change in pedagogy for teachers, we expect students to make the adjustments as learners to this expected practice immediately as they enter classrooms such as Tyler's. The inherent intentions of our Chemistry curriculum and changed practices of our teachers bring requirements for change for students in their 'studenting' (Mason \& McFeetors, 2006); that is what they need to do succeed as participants in school in terms of achievement and behavior, especially in adapting to a discursive rather than univocal classroom. Tyler's students provide indication that this aspect of studenting is something they would prefer to see scaffolded. As Kitchen (2004) identifies and is evidenced in Tyler's students, student resistance to educational reform and the dialogic classroom environment often promoted by such reform is not uncommon. We still speculate that student resistance is more of a legitimate apprehension grounded in their underdeveloped communication skills required and rewarded in the nature of the curriculum and the pedagogy it encourages. Only through scaffolded practice can we expect students to conceptually move back and forth among these modalities and cognitively interact with various types of representations in a meaningful way

Although the new Chemistry curricula and its tetrahedral, learner-centered orientation are based upon a consideration of what contributes to student learning, it is likely the curriculum writers, professional development providers and teachers were somewhat naïve in their understanding of some finer issues related to individual student-learning preferences. The curriculum and the development team assumed, as Bourdieu (1990) challenges, that there is uniformity of all students; that is, that all students are to benefit equally by a tetrahedral Chemistry teaching orientation that focuses on discursive learning activities. As described by Denessen (1999), Tyler's pupil-oriented ideology focuses on a pedagogical relation that attempts to foster learning through involvement in dialogic processes. Tyler's experience would suggest that although students are, overall, responding positively to a teaching orientation that is tetrahedral in its orientation, there are tensions associated with his pedagogy and the curriculum's expectations, especially in terms of the discourse it requires in his classroom and the changing emphases that are manifest in assessment practices. As Tyler states, "he is just not there yet" in addressing the tension between a curriculum orientation and pedagogy that is more dialogical, and students whose preference is for less dialogic processes. Until that time, some students are likely to continue to hold a view that the discursive classroom with its emphasis on assessment practices that require a broader range of communication skills are likely to favor those with 


\section{Responding to Students' Learning Preferences in Chemistry}

the ability to speak the language. This change in studenting requires them to acquire a new way of relating to and using language (Bourdieu, 1990; Halliday \& Martin, 1993). As recently identified by Ryu (2012), reform-based science education policy that presumes classroom discursive practices benefit any student must be challenged through consideration of the sociocultural position of students represented in classrooms.

We believe Mezirow's transformational learning model underpins the learning Tyler has begun to experience. Although we have 'learned' as the larger and much longer professional development has progressed, the learning that has occurred, or at least set in motion, by soliciting students' responses to their students' teaching has been epochal (Mezirow, 1981). That is, it has immediately triggered 'disorientation' through the examination of the data that identify congruence and, more importantly, incongruence between student and teacher, and among student perceptions. This disorientation has primarily been grounded in disturbing a teacher's sub-identity, in Tyler's case moving from being an advocate for studentcentered curriculum to a teacher in practice responsive to the learning preferences of individual students. Tyler gives a good example of a teacher believing in and responding to a learner-centered curriculum, but not recognizing the implications of such a curriculum in regards to the individual learning preferences of his students. The breadth of the teacher behaviors he uses and the frequency of their use testify to a teacher's aspiration to focus on student learning through applying a tetrahedral orientation in his pedagogy. As Tyler stated:

It was what $I$ thought they needed to help them learn. I realize now I need to listen to my students and hear what they're saying to really help them along [in their learning]. It's like there's another level I need to move to and I see it as a challenge. I haven't sorted that one out yet.

Despite the tentativeness of his response, Tyler's journey gives testament to a teacher who is working through his teacher practices in order to respond to the learning preferences of his individual students especially in terms of the communication pattern requirements of the Chemistry classroom. As Ryu (In Press) encourages, Tyler has taken on board awareness that his pedagogy must give consideration to the sociocultural position of students represented in classrooms. Similarly, we as professional development providers and Chemistry curriculum writers need to make explicit the need for adjusted practices for a curriculum that assumes that discursive classroom practices are favored by and equitable for all.

\section{Summary}

In this study we have followed a teacher's journey in addressing a puzzlement both we as curriculum writers, professional development providers and teachers share. How do students respond to the introduction of a new learnercentered Chemistry curriculum and the associated discursive practices required by his pedagogy? As well, what is the source 


\section{Responding to Students' Learning Preferences in Chemistry}

of any tensions evident between teachers and students and among students in response to new pedagogy? Further, what is the influence of these tensions on a teacher's teaching? Tyler's account provides evidence that reform efforts in Chemistry education, although student-centered because they are grounded in learning theory, are likely to require significant changes in both teacher and student behaviors. The teachers we have worked as Kane and Maw (2005) suggest were 'the willing' and attention is given to their needs and concerns, often resulting in gradual changes in their pedagogy with little regard for students in terms of the changes this requires of their experiencing, thinking and, in this case, communicating.

We believe that the process we have used in working with Tyler using the congruence and incongruence of perceptions of preferred teaching practices elucidated through the Chemistry Teaching Inventory and student-response form, the Chemistry Classroom Inventory provide a purposeful means to destabilize teachers' thinking, purposely 'problematize' teaching and encourage their change. The data gathered and critical discourse that follow become essential processes in fostering teachers' learning and adjusted practice towards a truly student-centered pedagogy where they see further need to respond to the individual learning preferences of their students. As a result, students are given the opportunity to be agents for change in bringing pedagogy in congruence with the ways in which they learn. Based upon these positive outcomes, we encourage professional development programs to give agency to students in advocating for change. It's possible that the topdown measures used to bring about teacher change are better served by ensuring the inclusion of bottom-up processes that use the authority of student voice to trigger the disequilibrium necessary for such transformational processes to occur in support of students and their learning. 


\section{Responding to Students' Learning Preferences in Chemistry}

\section{References}

Ardac, D., \& Akaygun, S. (2004). Effectiveness of multimedia instruction that emphasize molecular representation of students' understanding of chemical change. Journal of Research in Science Teaching, 41(4), 317-337.

Berry, A. (2007). Tensions in teaching about teaching: Developing practice as a teacher educator. Dordrecht: Springer.

Bindernagel, J., \& and Eilks, I. (2009). Evaluating roadmaps to portray and develop chemistry teachers' PCK about curricular structures concerning sub-microscopic models. Chemistry Education Research and Practice, 10, 77-85.

Bishop, R. (1996). Collaborative research stories: Whakawhanaungatanga. Palmerston North: Dunmore Press.

Bogdan, R. C., \& Biklen, S. K. (1992). Qualitative research for education: An introduction to theory and methods (2nd ed.). Boston, MA: Allyn \& Bacon.

Bourdieu, P. (1990). Reproduction: In education, society and culture. London: Sage Publications.

Bunce, D. \& Gabel, D. (2002). Differential effects on the achievement of males and females of teaching the particulate nature of chemistry. Journal of Research in Science Teaching, 39(10), 911 - 927.

Burmesiter, M., Rauch, F., \& Eilks, I. (2012). Education for sustainable development (ESD) and chemistry education. Chemistry Education Research and Practice, 13, 59-68.

Cattley, G. (2007). Emergence of professional identity for the pre-service teacher. International Education Journal, 8(2), 3337-47.

Cook-Sather, A. (2002). Authorizing students' perspectives: toward trust, dialogue, and change in education. Educational Researcher, 31(4), 3-14.

De Haan, G. (2006). The BLK '21' program in Germany: a 'Gestaltungskompetenz'-based model for education for sustainable development. Environmental Education Research, 12, 19-32.

Denessen, E. (1999). Beliefs about education: Content- and pupil-orientedness in the Netherlands. Leuven-Apeldoorn: Garant.

Fraser, B.J. (1998a). Science learning environments: Assessments, effects, and determinants. In B.J. Fraser \& K.G. Tobin (Eds.), International handbook of science education (pp. 1-61). London: Kluwer.

Fraser, B.J. (1998b). Classroom environment instruments: Developments, validity and applications. Learning Environment Research: An International Journal, 1, 7-33.

Fullan, M. (1992). Successful school improvement. Buckingham: Open University Press. 


\section{Responding to Students' Learning Preferences in Chemistry}

Gabel, D. (1999). Improving teaching and learning through chemistry education research. Journal of Chemistry Education, $76,548-553$.

Gilbert J. K., (2005). Visualization: a metacognitive skill in science and science education. In J. K. Gilbert, (Ed.), Visualization in science education (pp. 9-27). Dordrecht: Springer.

Gilbert, J.K., Justi, R., van Dreil, J.H., De Jong, O., \& Treagust, D.F. (2004). Securing a future for chemistry education. Chemistry Education: Research and Practice, 5(1), 5-14.

Gilbert J. K. and Treagust D. F., (2008). Reforming the teaching and learning of the macro/submicro/symbolic representational relationship in chemical education, in B. Ralle and I. Eilks (Eds.). Promoting successful science learning - The worth of science education research (pp. 99-110). Aachen: Shaker,

Halliday, M., \& Martin, J. (1993). Writing science: Literacy and discursive power. Pittsburgh: University Of Pittsburgh Press.

Hoffmann, R. and Laszlo, P. (1991). Representation in chemistry. Angewandte Chemie, International Edition English, 30, $12-24$.

Hoffmann, R. and Laszlo, P. (2001). The say of things. Retrieved from http://www.pierrelaszlo.com/articles/9-sciencecommunication/57-the-say-of-things.

Johnstone, A.H. (1991). Why is chemistry difficult to learn? Things are seldom what they see. Journal of Computer-Assisted Learning, 7, 701-710.

Kane, R., \& Maw, N. (2005). Making sense of learning at secondary school: involving students to improve teaching practice. Cambridge Journal of Education, 35(3), 311-322.

Kegan, R. (1994). In over our heads: The mental demands of modern life. Cambridge, MA: Harvard University Press.

Kitchen, R. (2004). Challenges associated with developing discursive classrooms in high-poverty, rural schools. Mathematics Teacher, 97(1), 28-31.

Lamote, C., and Engels, N. (2010). The development of student teachers' professional identity. European Journal of Teacher Education, 33(1), 3-18.

Lewthwaite, Brian, and Wiebe, Rick (2011). Fostering teacher development to a tetrahedral orientation in the teaching of chemistry. Research in Science Education, 41 (5). pp. 667-689. 


\section{Responding to Students' Learning Preferences in Chemistry}

Mahaffy, P. (2006). Moving chemistry education into the 3D: A tetrahedral metaphor for understanding chemistry. Journal of Chemical Education, 83(1), 49-55.

Manitoba Education Citizenship and Youth (2006). Grade 11 Chemistry: A framework for implementation. Winnipeg: Manitoba Education, Training and Youth.

Manitoba Education Citizenship and Youth (2007). Grade 12 Chemistry: A Framework for Implementation. Winnipeg: Manitoba Education, Training and Youth.

Mason, R. T. \& McFeetors, P. J. (2007). Student trajectories in high school mathematics: Issues of choice, support, and identity-making. Canadian Journal of Science, Mathematics and Technology Education, 7(4), 291-316.

Mezirow, J. (1981). A critical theory of adult learning and education. Adult Education Quarterly, 32 (1), 3-24.

Mezirow, J. (Ed.). (2000). Learning as transformation: Critical perspectives on a theory in progress. San Francisco: JosseyBass.

Rivard, L \& Straw, S. (1990). The effect of talk and writing on learning science: An exploratory study. Science Education, 84(5), 566-593.

Ryu, M. (In Press). "But at school...I became a bit shy": Korean immigrant adolescents' discursive participation in science education. Culture Studies of Science Education.

Rots. I. (2007, July). An exploratory study on the relationship between teacher education graduates' professional identity and their views on teacher education presented at the meeting of International Study Association on Teachers and Teaching

Stake, R. (1995). The art of case research. Thousand Oaks: Sage Publications.

Taber, K. S. (2013). Revisiting the chemistry triplet: drawing upon the nature of chemical knowledge and the psychology of learning to inform chemistry education. Chemistry Education Research and Practice. doi: 10.1039/C3RP00012E

von Glasersfeld, E. (1995). Radical constructivism: A way of knowing and learning. London: The Falmer Press.

Wu, H.-K. (2003). Linking the microscopic view of chemistry to real life experiences: Intertextuality in a high-school science classroom. Science Education, 87, 868-891. 


\section{Responding to Students' Learning Preferences in Chemistry}

\section{Chemistry Teacher Inventory (CTI) Grade:}

There are 33 items in this questionnaire pertaining to strategies or actions used in the teaching of chemistry. They are statements to be considered in the context of one chemistry class in which you work. Think about how well the statements describe your teaching of chemistry in this class. If you teach more than one class and you believe your teaching is different in this other setting you might consider completing a further CTI for this other setting.

Indicate your answer on the score sheet by circling:

$\mathrm{N} \quad$ if you never use this strategy in your teaching of chemistry;

$\mathrm{S} \quad$ if you rarely use this strategy in your teaching of chemistry;

$\mathrm{F}$ if you sometimes use this strategy in your teaching of chemistry;

0 if you often use this strategy in your teaching of chemistry:

A if you almost always use this strategy in your teaching of chemistry;

If you change your mind about a response, cross out the old answer and circle the new choice.

1. Students copy notes from overheads without explanations. I perform chemical demonstrations.

3. Visual images are used to clarify Chemistry ideas.

4 Students plan investigations and then carry out the investigation.

5. Computer-based simulations are used to clarify Chemistry ideas.

6. I explain how chemistry topics relate to students' lives.

7. I talk about the historical development of Chemistry ideas.

8. Students carry out prescribed or set labs.

9. Students do laboratory formal write-ups.

10. Students are provided with pre-written notes and they are discussed.

11. Students are asked to explain what has been demonstrated.

12. Students perform calculations.

13. Students use manipulatives to help understand what is happening at the molecular level.

14. Students are required to know what a formula means before they calculate.

15. Students have to explain chemistry ideas at the molecular level.

16. I use a variety of strategies to get across Chemistry ideas.

17. On tests students perform calculations.

18. Students make notes from textbooks.

19. Students are assigned problems from texts.

20. Students work together on tasks.

21. Students are expected to explain their results by discussing with their group. N

22. I use analogies or role plays to get across chemistry ideas.

23. I check to see if students grasp ideas before moving on to the next topic.

24. I refer to the history of chemistry applications in my teaching.

25. Chemical models are used to help students to learn.

26. Min-labs/short experiments are performed by students.

27. I assess student learning by tests.

28. I give students lots of examples to help assist them in their learning.

29. I get students to work together and help each other on activities \& problems $N$

30. I assist students with their work as they request assistance.

31. I use everyday examples to communicate Chemistry ideas.

32. I explain ideas as students copy notes.

33. I assess student learning of student experimental activities.

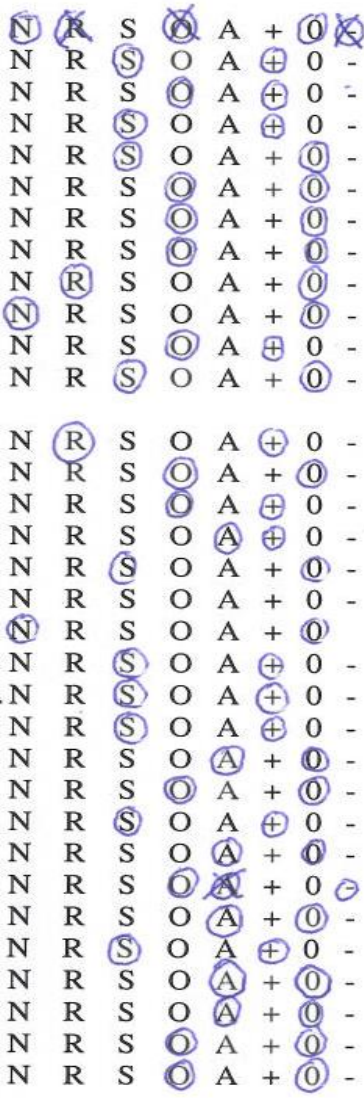

Thanks for completing this questionnaire. 


\section{Responding to Students' Learning Preferences in Chemistry}

\section{Appendix B}

\section{Chemistry Classroom Inventory (CCI)

\author{
Grade:
}

There are 33 items in this questionnaire pertaining to activities that may be occurring in this classroom. They are statements to be considered in the context of the chemistry class in which you are in currently. Think about how well the statements describe your chemistry classroom. Your answers will help me to understand what I can be doing better to help you in your chemistry learning.

Indicate your answer on the score sheet by circling:

$\mathrm{N} \quad$ if you never see this happen in your chemistry classroom;

if you seldom see this happen in your chemistry classroom;

if you frequently see this happen in your chemistry classroom;

A if you always see this happen in your chemistry classroom.

If you change your mind about a response, cross out the old answer and circle the new choice.

1. I copy notes from overheads without explanations.

2. I observe chemical demonstrations.

3. Visual images are used to clarify Chemistry ideas.

4 I plan investigations and then carry out the investigation.

5. Computer-based simulations are used to clarify Chemistry ideas.

6. I learn about chemistry topics that are related to my life.

7. We talk about the historical development of Chemistry ideas.

8. I carry out prescribed or set labs.

9. I do laboratory formal write-ups.

10. I am provided with pre-written notes which may be discussed.

11. I am asked to explain what has been demonstrated.

12. I perform calculations.

13. I use manipulatives to help understand what is happening at the molecular level.

14. I am taught what a formula means before I calculate.

15. I have to explain chemistry ideas at the molecular level.

16. A variety of strategies are used to get across Chemistry ideas.

17. On tests I perform calculations.

18. I make notes from textbooks.

19. I am assigned problems from texts.

20. I work on tasks with classmates (pairs, groups, etc.).

21. I am expected to explain results by discussing with my group.

22. Analogies or role plays are used to get across chemistry ideas.

23. Enough time is provided to grasp ideas before moving on to the next topic.

24. The history of chemistry applications is talked about in my classroom.

25. Chemical models are used to help me learn.

26. Mini-labs/short experiments are performed.

27. I am assessed by tests.

28. I am given lots of examples to help assist me in my learning.

29. We work together and help each other on activities and problems.

30. The teacher assists me with my work as I need assistance.

31. Everyday examples are used to understand Chemistry ideas.

32. Ideas are explained as I copy or write notes.

33. I am assessed by lab reports.

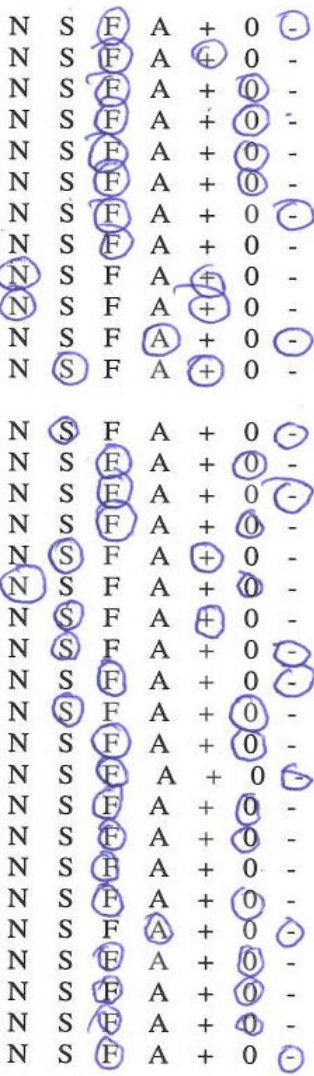

Thanks for completing this questionnaire. 